\title{
Bifidogenic and Antioxidant Activity of Exopolysaccharides Produced by Lactobacillus rhamnosus E/N Cultivated on Different Carbon Sources
}

\author{
MAGDALENA POLAK-BERECKA $^{1 *}$, ADAM WAŚKO $^{1}$, DOMINIK SZWAJGIER ${ }^{1}$ and ADAM CHOMA ${ }^{2}$ \\ ${ }^{1}$ Department of Biotechnology, Human Nutrition and Science of Food Commodities, \\ University of Life Sciences in Lublin, Skromna 8, 20-704 Lublin, Poland \\ ${ }^{2}$ Department of Genetics and Microbiology, Institute of Microbiology and Biotechnology, \\ Maria Curie-Skłodowska University, Akademicka 19, 20-033 Lublin, Poland
}

Received 11 September 2012, revised 7 February 2013, accepted 12 March 2013

Abstract

Lactobacillus rhamnosus $\mathrm{E} / \mathrm{N}$ is a probiotic bacterium, which synthesizes exopolysaccharides (EPS) with significant bifidogenic and antioxidant activities. The sugar composition of the EPSs produced depended on carbohydrates used as a carbon source in the growth media. Five Bifidobacterium strains were tested in vitro for their ability to utilize all the EPSs studied. The highest bifidogenic activity was revealed by EPSs obtained from Lactobacillus cultures supplemented with Gal, Lac, and Mal as the only carbon source, while significant antioxidant effects were observed in EPSs isolated from growth media enriched with galactose, lactose, and sucrose.

Ke y w ords: Lactobacillus rhamnosus, exopolysaccharides (EPSs), antioxidant activity, bifidogenic effect

Lactobacillus rhamnosus $\mathrm{E} / \mathrm{N}$ belongs to lactic acid bacteria (LAB) and is a probiotic microorganism, which secretes significant amounts of extracellular polysaccharides. Exopolysacharides (EPSs) from LAB can exert functional effects on foods, improve the rheology of fermented milk products, and have beneficial health effects. In particular, LAB EPSs have immunostimulatory activities (Chabot et al., 2001; Duboc and Mollet, 2001; Jolly et al., 2002). Moreover, these polymers enhance colonization of the gastrointestinal tract by probiotic bacteria and act as antioxidants (Hugenholtz and Smid, 2002; Badel et al., 2011). Dal Bello and coworkers (2001) as well as Korakli and coworkers (2002) pointed to the influence of EPS from Lactobacillus sanfranciscensis on bifidobacterial metabolism. A large group of food-grade bacteria are producers of nondigestible carbohydrates, which have bifidogenic activity (Hugenholtz and Smid, 2002). Moreover, EPS obtained from a culture of Lactococcus lactis subsp. lactis, mainly composed of fructose and rhamnose, showed strong antioxidant capacity, i.e. the ability to inhibit hydroxyl and superoxide anion radical activities (Pan and Mei, 2010). A majority of the bifidogenic compounds described so far were carbohydrates of plant origin (Su et al., 2007). However, until now, no data have been published on selective stimulation of the growth of Bifidobacterium or on the antioxidant action of $L b$. rhamnosus EPSs.

Heteropolysaccharides derived from Lactobacillus spp. show great variability in their monomer composition, charge, spatial arrangement, and rigidity (Duboc and Mollet, 2001). A majority of exopolysaccharide backbones have repeating units composed of glucose, galactose, and rhamnose, which occur in different ratios, different anomeric configuration and are connected by different linkages. Occasionally, aminosugars such as $\mathrm{N}$-acetyl-D-glucosamine and $\mathrm{N}$-acetyl-Dgalactosamine as well as non-carbohydrate substituents (sn-glycerol-3-phosphate, phosphate, and acetyl groups) may also be present in EPSs (De Vuyst and Degeest, 1999; Badel et al., 2011). There is some evidence for a correlation between the structure of EPS and its ability to interact with proteins (Ruas-Madiedo et al., 2002). It can also be assumed that the structure-function relationships in these biopolymers are crucial for their specific biological actions such as the bifidogenic and antioxidant effects. The knowledge of this correlation is particularly important as it provides a foundation for producing functionally valuable exopolysaccharides. Growth conditions and the medium components may

\footnotetext{
* Corresponding author: M. Polak-Berecka, Department of Biotechnology, Human Nutrition and Science of Food Commodities, University of Life Sciences in Lublin, Skromna 8, 20-704 Lublin, Poland: phone: +48 814623 356; fax: +48 8146 23 400, e-mail: 3mj@wp.pl
} 
affect the yield and sugar composition of EPSs (Looijesteijn et al., 2000). The carbon source seems to be one of the most important factors influencing the monomeric composition and variations in the glycosidic bonds of EPS (De Vuyst and Degeest, 1999). Grobben etal. $(1995 ; 1996)$ have reported that the composition of EPS produced by Lactobacillus delbrueckii subsp. bulgaricus depended on the culture components and conditions of cultivation of bacteria.

In the present paper, the exopolysaccharides synthesized by L. rhamnosus $\mathrm{E} / \mathrm{N}$ growing on different sugarsupplemented media were tested in respect of their composition. The bifidogenic potential and antioxidant effects of these EPSs were estimated as well.

\section{Experimental}

\section{Materials and Methods}

Bacterial strains and growth conditions. L. rhamnosus E/N, obtained from Biomed Serum and Vaccine Production Plant Ltd., (Lublin, Poland), was stored at $-80^{\circ} \mathrm{C}$ in the MRS (de Man et al., 1960) medium supplemented with $20 \%$ (v/v) glycerol. This strain is deposited at the Institute of Biochemistry and Biophysics of the Polish Academy of Sciences under number 2594 and is one of the components of Lakcid ${ }^{\oplus}$, a pharmaceutical product containing viable probiotic bacteria. The strain was revitalized in MRS broth at $37^{\circ} \mathrm{C}$ for $24 \mathrm{~h}$ before use. Bifidobacterium infantis ATCC1567 was obtained from the American Type Culture Collection (ATCC, Manassas, Va., U.S.A., http://www.atcc.org/). Bifidobacterium bifidum B 41410, Bifidobacterium animalis subsp. lactis B 41406, B. animalis BI 30, and Bifidobacterium longum KN 29 were kindly provided by Prof. M. Bielecka (Department of Food Microbiology, Institute of Animal Reproduction and Food Research, Polish Academy of Sciences in Olsztyn, Poland). The strains were cultured on Garche's medium (Rasic 1990) $(10 \mathrm{ml})$ at $37^{\circ} \mathrm{C}$ in test tubes. Anaerobic conditions were obtained by injecting $0.5 \mathrm{ml}$ of $15 \%(\mathrm{~m} / \mathrm{v}) \mathrm{NaHCO}_{3}$ and $0.5 \mathrm{ml}$ of $20 \%(\mathrm{~m} / \mathrm{v})$ pyrogallol solutions in water into cotton stoppers followed by aseptic sealing of the tubes with parafilm.

For EPS extraction, Lb. rhamnosus E/N was cultivated in a bioreactor (Sartorius, Goettingen, Germany) in 1.51 of the MRS medium supplemented with appropriate sugar $(20 \mathrm{~g} / \mathrm{l}$; glucose, galactose, sucrose, maltose, and lactose) as the only carbon source. Batch culture inoculated with the Lb.rhamnosus $\mathrm{E} / \mathrm{N}$ overnight culture $(2.5 \%, \mathrm{v} / \mathrm{v})$ was carried out for $68 \mathrm{~h}$ at $37^{\circ} \mathrm{C}$ at a constant $\mathrm{pH}$ of 6.3 . After isolation (by precipitation with $96 \%$ ethanol, see below) and lyophilisation, the following EPS preparations were obtained: EPS-Glc, EPS-Gal, EPS-Mal, EPS-Suc, and EPS-Lac.
Preparation of exopolysaccharides. After incubation, the cultures were heated at $100^{\circ} \mathrm{C}$ for $15 \mathrm{~min}$, and bacterial cells were removed by centrifugation $(4,000 \times g, 30 \mathrm{~min}$, room temperature). The supernatant volumes were reduced ( 3 times) by evaporation using a vacuum rotary evaporator (Büchi R210: 0.093 MPa, $40^{\circ} \mathrm{C}$ ). The EPSs were precipitated by adding three volumes of chilled $96 \%$ ethanol. The mixtures were left for $24 \mathrm{~h}$ at $4^{\circ} \mathrm{C}$. The exopolysaccharides were collected by centrifugation at $20,000 \times g$ for $30 \mathrm{~min}$ at $4^{\circ} \mathrm{C}$, dissolved in distilled water, and dialyzed $(4,000 \mathrm{Da}$ molecular weight cutoff membranes, Roth, Karlsruhe, Germany) against distilled water for $48 \mathrm{~h}$ at $4^{\circ} \mathrm{C}$. The water was changed twice. The crude freeze-dried EPSs were purified by dissolving in 15\% trichloroacetic acid (TCA), and precipitated materials were removed by centrifugation $(20,000 \times g)$. The purified EPSs were exhaustively dialyzed and finally lyophilized.

Production of exopolysaccharides by Lb. rhamnosus $\mathrm{E} / \mathrm{N}$ was determined by measuring protein and carbohydrate concentrations. The total sugar content was determined by the method of Dubois et al. (1956), using glucose as a standard. The protein content was determined with the method of Bradford (1976), using bovine serum albumin (Sigma Company, USA) as a standard.

In order to eliminate any contamination of the EPSs derived from the MRS medium (sugars and aminosugars), the same procedures were used for precipitation of high molecular weight substances from the noninoculated medium.

Compositional analysis. For qualitative analysis, the exopolysaccharides were subjected to methanolysis in $1 \mathrm{M} \mathrm{HCl}$ in $\mathrm{MeOH}\left(0.5 \mathrm{ml}, 80^{\circ} \mathrm{C}, 20 \mathrm{~h}\right)$. The samples were dried and acetylated with a mixture of $\mathrm{Ac}_{2} \mathrm{O}$ and pyridine $\left(1: 1, \mathrm{v}: \mathrm{v}, 50 \mu \mathrm{l}, 100^{\circ} \mathrm{C}, 30 \mathrm{~min}\right)$. The quantitative estimations of neutral and amino sugars isolated from the EPSs were based on analysis of alditol acetates. To this point, the exopolysaccharides were hydrolyzed with $2 \mathrm{M}$ TFA $\left(100^{\circ} \mathrm{C}, 4 \mathrm{~h}\right)$ and, after drying, the samples were subjected to $\mathrm{N}$-acetylation (Que et al., 2000) followed by reduction with $\mathrm{NaBH}_{4}$ and peracetylation (Sawardeker etal., 1965). Alditol acetates as well as acetylated methyl glycosides were analyzed using combined gas chromatography-mass spectrometry. GLCMS analyses were carried out on a Hewlett-Packard gas chromatograph (model HP5890A) equipped with a capillary column (HP-5MS, $30 \mathrm{~m} \times 0.25 \mathrm{~mm}$ ) and connected to a mass selective detector (MSD model HP 5971). Helium was the carrier gas, and the temperature program was initially $150^{\circ} \mathrm{C}$ for $5 \mathrm{~min}$, then raised to $310^{\circ} \mathrm{C}$ at a ramp rate of $3^{\circ} \mathrm{C} / \mathrm{min}$, final time 20 minutes.

Bifidogenic effect of exopolysaccharides (in vitro assay). Prior to testing the effect of EPS on the growth of bifidobacterial strains, an optimal basal medium was chosen. Several media were tested: 152.CECT 
Bifidobacterium sp. medium without a carbon source (Espinosa-Martos and Rupérez, 2009) and modified Garche's media (González et al., 2008) containing peptone $20 \mathrm{~g} / \mathrm{l}$, yeast extract $2 \mathrm{~g} / \mathrm{l}, \mathrm{HCl}$ cysteine $0.4 \mathrm{~g} / \mathrm{l}$, sodium acetate $6 \mathrm{~g} / \mathrm{l}, \mathrm{MgSO}_{4}{ }^{*} 7 \mathrm{H}_{2} \mathrm{O} 0.12 \mathrm{~g} / \mathrm{l}, \mathrm{Na}_{2} \mathrm{HPO}_{4}^{*}$ $12 \mathrm{H}_{2} \mathrm{O} 2.5 \mathrm{~g} / 1, \mathrm{~K}_{2} \mathrm{HPO}_{4} 2 \mathrm{~g} / \mathrm{l}$, and lactose in concentrations from 0.1 to $3 \mathrm{~g} / \mathrm{l}$.

Lyophilized exopolysaccharides were added to the basal medium to a final concentration of $0.5 \%(\mathrm{w} / \mathrm{v})$. The growth rate of each strain of Bifidobacterium on these media was monitored by measuring optical density $\left(\mathrm{OD}_{600}\right)$ using a Bioscreen $\mathrm{C}$ instrument (LabSystem, Finland). Three hundred and fifty $\mu$ of the test media were inoculated with an overnight culture of actively growing Bifidobacterium cells $(50 \mu \mathrm{l})$. The surfaces of the cultures were covered with $20 \mu \mathrm{l}$ of sterile paraffin. All the experiments were carried out in honeycomb plates at $37^{\circ} \mathrm{C}$ for $96 \mathrm{~h}$.

Antioxidant activities of EPS (measured using ABTS). The atioxidant properties of EPSs were estimated using a slightly modified method of Miller et al. (1993). The reagents (in $5 \mathrm{mM}$ phosphate buffer, $\mathrm{pH} 7.0$ ) were present in the reaction mixture at final concentrations of $0.15 \mathrm{mM}$ ABTS (2,2'-azino-bis(3-ethylbenzothiazoline-6-sulphonic acid); $0.0025 \mathrm{mM}$ myoglobin, and $0.375 \mathrm{mM} \mathrm{H}_{2} \mathrm{O}_{2}$. The EPS solution in double distilled (DDI) water $(0.03 \mathrm{ml}, 5 \mathrm{mg} / \mathrm{ml})$ was mixed with $0.03 \mathrm{ml}$ of the buffer and $0.28 \mathrm{ml}$ of the ABTS/myoglobin reagent followed by addition of $0.023 \mathrm{ml}$ of $\mathrm{H}_{2} \mathrm{O}_{2}$ solution in water $\left(5.92 \mathrm{mM} / \mathrm{dm}^{3}\right)$ to start the reaction. Absorbance was measured every minute $(700 \mathrm{~nm}$, $20^{\circ} \mathrm{C}$ ) using a 96-well microplate reader (Tecan Sunrise, Austria). Reaction time of 15 minutes was selected for the calculations of the TEAC value. The synthetic antioxidant Trolox, a water-soluble vitamin E analogue, was used as an antioxidative standard. Fifteen Trolox standard solutions in the buffer $(0.041 \mathrm{mM}-0.615 \mathrm{mM})$ replaced $0.03 \mathrm{ml}$ of the tested sample. Total antioxidant activity was expressed in $\mathrm{mM}$ of Trolox (TEAC value), which inhibited the increase in absorbance to the same degree as the EPS solution. Blanks containing EPS and without EPS were run simultaneously for subtraction of background absorbances of the tested samples.

The method of Miller et al. (1993) in modifications proposed by Re etal. (1999) was also used. A solution of ABTS $(7 \mathrm{mM})$ containing potassium persulphate $(2.45 \mathrm{mM})$ was prepared and left for $24 \mathrm{~h}$ at ambient temperature. Directly prior to analysis, the absorbance of this solution (at $700 \mathrm{~nm}$ ) was adjusted to $0.70 \pm 0.02$. For measurements, $0.06 \mathrm{ml}$ of the ABTS/persulphate solution, $0.1 \mathrm{ml}$ of DDI water, and $0.15 \mathrm{ml}$ of the tested sample $(5 \mathrm{mg} / \mathrm{ml})$ were mixed. Absorbance was read at $700 \mathrm{~nm}$ after $10 \mathrm{~min}$ of the reaction $\left(20^{\circ} \mathrm{C}\right.$, microplate reader, Tecan Sunrise, Austria). Twenty Trolox standard solutions in DDI water $(0.4155 \mathrm{mM}-8.31 \mathrm{mM})$ were used for the calculation of the TEAC values as described above. Blanks were run as described above.

Statistical analysis. For each experiment, the optical density was given as mean \pm SD of triplicate samples from two independent experiments. The data were analyzed using the Excel statistical package. Statistical significances were determined by the Student's $t$-test and set at $P<0.01$.

\section{Results}

Compositional analyses of exopolysaccharides. The yields of EPS produced by Lb. rhamnosus E/N varied and were dependent on the carbon source in the growth medium (Table I). Lyophilized EPS contained from $92.05 \%$ to $97.45 \%$ carbohydrates and from $2.51 \%$ to $7.95 \%$ proteins, depending on the carbon source.

Chromatographic separation (GLC-MS) of acetylated methyl glycosides and alditol acetates obtained after acidic degradation of the carbohydrate polymers was the basic method of qualitative and quantitative analyses of the isolated EPSs. Glucose, galactose, mannose and 6-deoxyhexose (rhamnose) were found to be constituents of the investigated preparations. The results were corrected by subtraction of sugar amounts characteristic for carbohydrate polymers precipitated from the non-inoculated MRS medium (data not shown). The contents of sugars in each EPS preparation are expressed in mol\% and listed in Table II. The

Table I

Yields of exopolysaccharides synthesized by Lactobacillus rhamnosus $\mathrm{E} / \mathrm{N}$ on media with different carbon sources

\begin{tabular}{|l|c|c|c|}
\hline $\begin{array}{c}\text { Carbon } \\
\text { source }\end{array}$ & $\begin{array}{c}\text { EPS, } \\
\mathrm{mg} / 11\end{array}$ & $\begin{array}{c}\text { \% of } \\
\text { carbohydrates }^{*}\end{array}$ & $\begin{array}{c}\text { \% of } \\
\text { proteins }^{* *}\end{array}$ \\
\hline Galactose & 81.08 & 96.12 & 3.88 \\
\hline Lactose & 219.25 & 97.18 & 2.82 \\
\hline Glucose & 130.08 & 97.41 & 2.59 \\
\hline Saccharose & 31.55 & 92.64 & 7.36 \\
\hline Maltose & 37.37 & 93.18 & 6.82 \\
\hline
\end{tabular}

* - estimated by the Dubois method

** - estimated by the Bradford method

Table II

Carbohydrate composition of exopolysaccharides produced by Lactobacillus rhamnosus $\mathrm{E} / \mathrm{N}$ cultivated on different carbon sources

\begin{tabular}{|l|c|c|r|r|}
\hline \multirow{2}{*}{$\begin{array}{c}\text { EPS } \\
\text { (carbon sources) }\end{array}$} & \multicolumn{4}{c|}{ Sugars (mol\%) } \\
\cline { 2 - 5 } & Rha & Man & Glc & Gal \\
\hline EPS-Gal & 47.9 & 5.9 & 33.9 & 12.3 \\
\hline EPS-Glc & 63.1 & 0.0 & 32.6 & 4.2 \\
\hline EPS-Suc & 100 & 0.0 & 0.0 & 0.0 \\
\hline EPS-Lac & 32.6 & 32.7 & 25.1 & 9.5 \\
\hline EPS-Mal & 17.6 & 65.4 & 16.9 & 0.0 \\
\hline
\end{tabular}



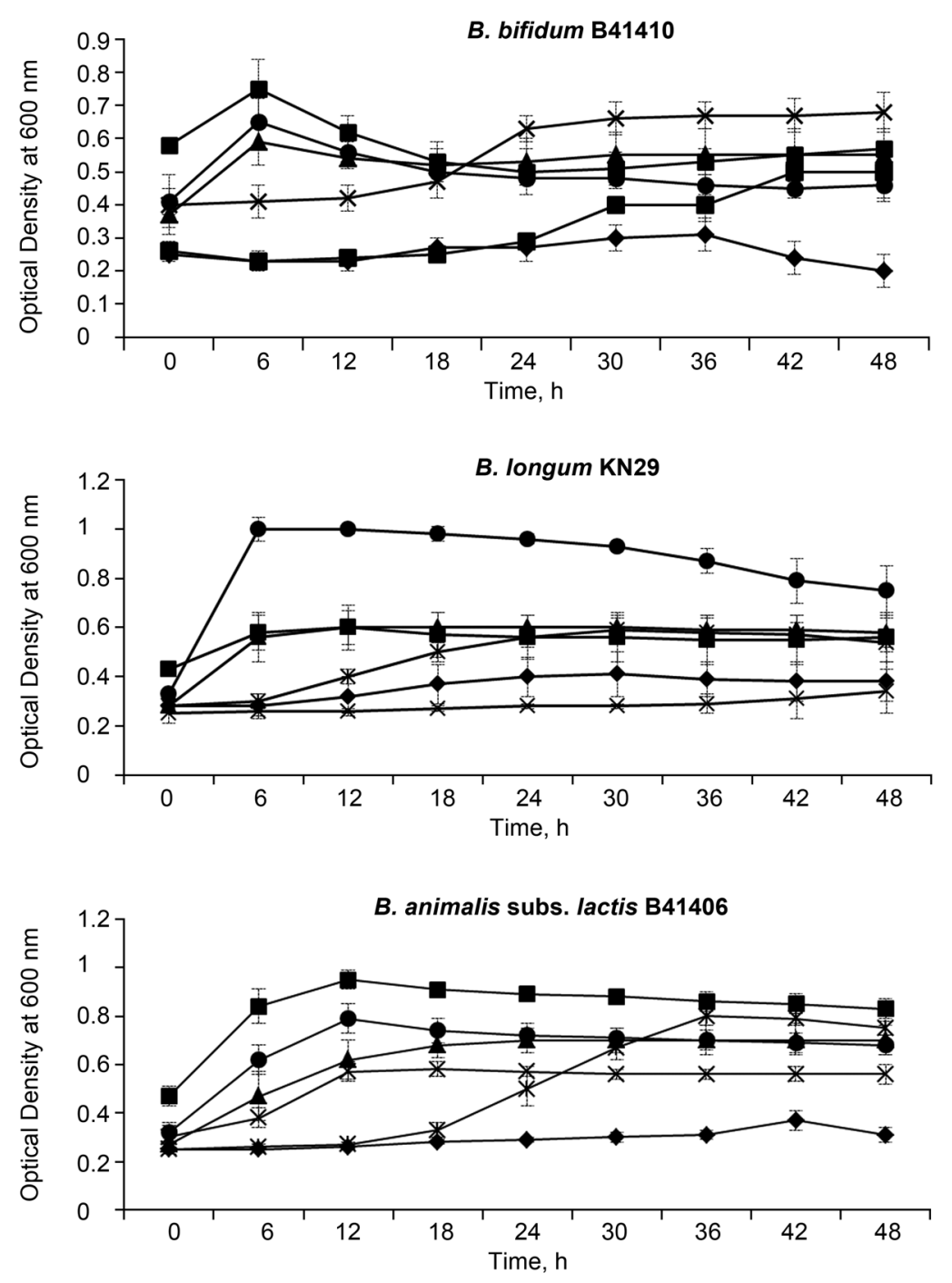

B. infantis ATCC1567
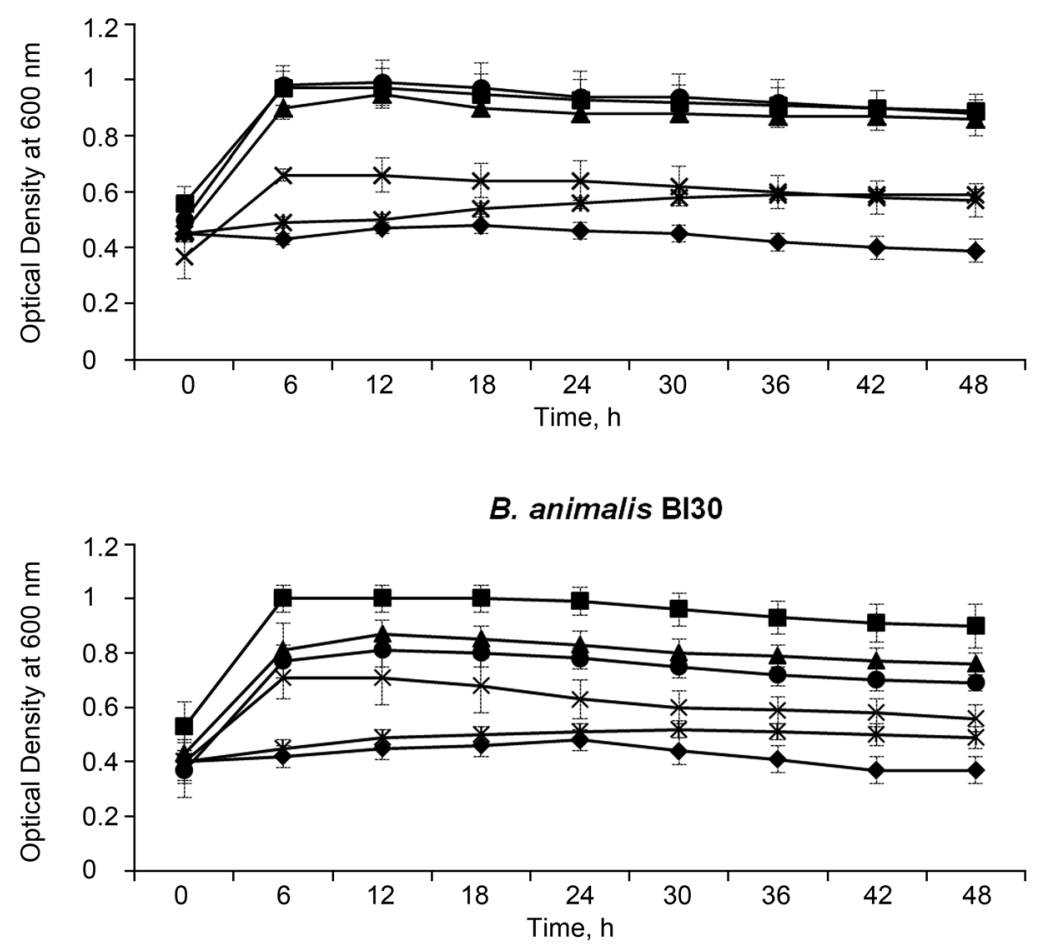
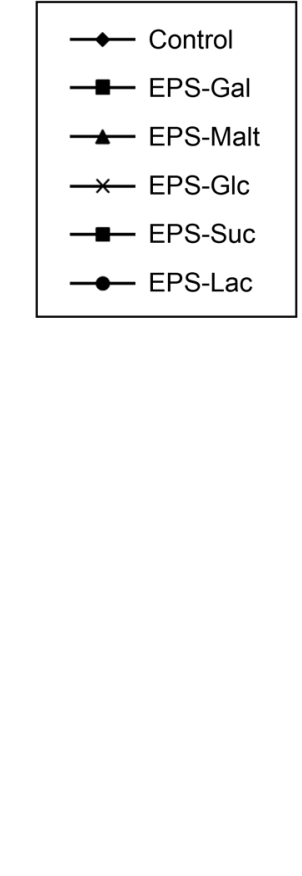
Fig. 2. Increase in absorbance at $700 \mathrm{~nm}$ due to the generation of ABTS radicals by myoglobin and $\mathrm{H}_{2} \mathrm{O}_{2}$ in the presence of EPS (mean values)

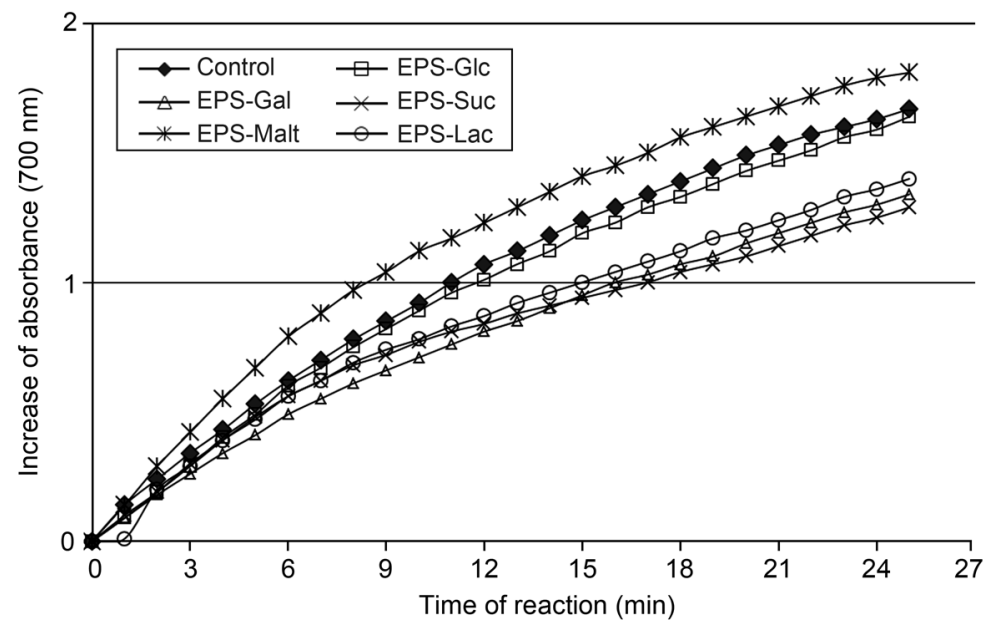

results obtained unequivocally indicate that the carbon source in the growth medium significantly influences the production and composition of exopolysaccharides synthesized by Lb.rhamnosus E/N. The EPS preparations have distinctly different sugar compositions and, presumably, different structures. EPS-Suc was identified as a homopolysaccharide composed of rhamnose. Both rhamnose and glucose were the major components of the other EPS preparations. Exopolysaccharides denoted as EPS-Mal contained a substantial amount of mannose; hence, they can be classified as mannans. Rhamnose was present in an amount comparable to the glucose and mannose content only in the EPS-Lac preparation. Galactose was always a minor component of the EPS preparations. Especially EPS-Glc contained a low amount of galactose; therefore, this sugar should be treated as a nonstoichiometric branching residue.

Bifidogenic effect of exopolysaccharides (in vitro assay). The basal media tested showed differences in supporting the growth of bifidobacteria (results not shown). The best results were obtained for Garche's modified medium containing $0.1 \mathrm{~g} / \mathrm{l}$ of lactose. Therefore, it was chosen as a basal medium for further experiments. Bifidobacterium microcultures grown in this medium reached an $\mathrm{OD}_{600}$ of 0.3 to 0.4 , whereas those grown in original Garche's medium had an $\mathrm{OD}_{600}$ of about 3.0.

The results of the analysis of bifidobacterial growth with Garche's basal medium supplemented with different EPS preparations showed that the growth of B. bifidum B 414010, B. animalis subsp. lactis B 41406, and B.animalis Bi30 was stimulated by all the EPSs tested. However, the growth of B. longum KN29 was not stimulated by EPS-Glc (Fig. 1). Generally, the EPSGal, EPS-Lac, and EPS-Mal preparations showed high bifidogenic activity. For B. bifidum B 414010 grown in a medium with EPS-Glc, a long lag phase was observed followed (after $18 \mathrm{~h}$ ) by active cell multiplications causing the highest optical density of the culture, indicating the best bifidogenic effect of EPS-Glc on this bacterial species. A similar growth curve was observed for B. animalis B41406 cultivated in a medium supplemented with EPS-Suc.

Antioxidant activities of EPS. The antioxidant activities of the EPS polymers were studied by two methods. The method utilizing the ABTS/myoglobin reagent is rapid and suitable for measurement of both antioxidant and prooxidant activities. The method with ABTS/potassium persulphate is suitable for detection of the free radical "scavenging" ability but not for measurement of the prooxidant action.

The antioxidant activities of the EPS-Glc, EPSGal, EPS-Suc, and EPS-Lac preparation s were proved using the ABTS/myoglobin method, whereas EPS-Mal exhibited prooxidant activity over the whole time range (Fig. 2).

The TEAC values were calculated on the basis of the absorbance readings within $15 \mathrm{~min}$ after the beginning of the reaction (Fig. 3). EPS-Suc and EPS-Gal exhibited the highest TEAC values $(0.50 \mathrm{mM}$ and $0.49 \mathrm{mM}$, respectively) with an insignificant $(\mathrm{p}>0.05)$ difference between the two polymers. EPS-Lac exhibited

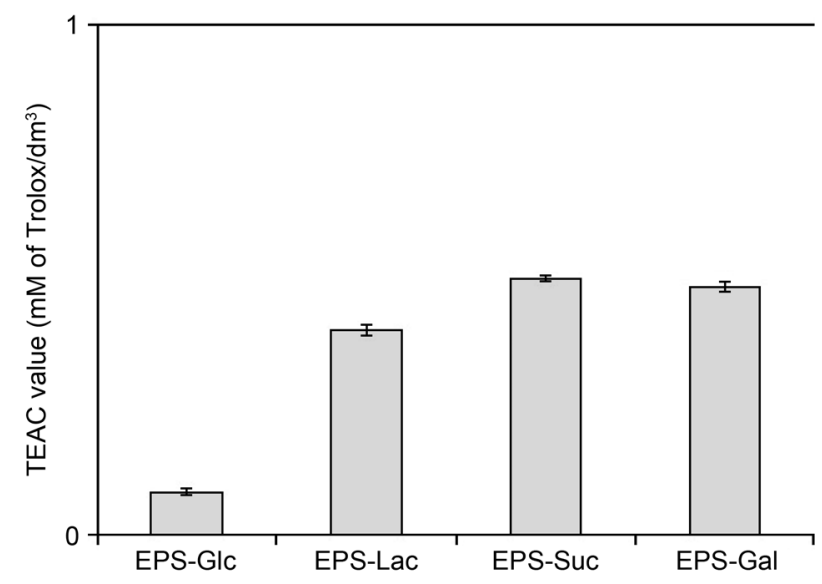

Fig. 3. Antioxidant activities of EPS measured using ABTS/myoglobin and $\mathrm{H}_{2} \mathrm{O}_{2}($ mean $\pm \mathrm{SD})$ 


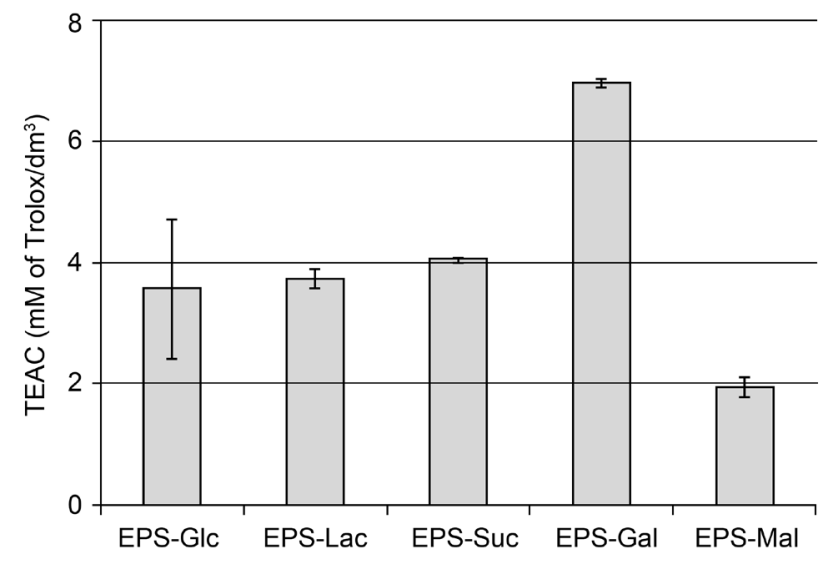

Fig. 4. Antioxidant activities of EPSs measured using the method with $\mathrm{ABTS} /$ potassium persulphate (mean $\pm \mathrm{SD}$ )

significantly $(\mathrm{p}<0.05)$ lower antioxidant activity $(0.40 \mathrm{mM})$ than EPS-Suc and EPS-Gal, but significantly $(\mathrm{p}<0.05)$ higher than EPS-Glc $(0.08 \mathrm{mM})$.

Each exopolysaccharide polymer effectively "scavenged" ABTS radicals (Fig. 4). However, free radicals were "scavenged" to a different extent by the EPSs tested. It is interesting to note that among the polysaccharides studied, EPS-Gal exhibited the highest ability to remove ABTS radicals (TEAC $6.96 \mathrm{mM}$ ).

\section{Discussion}

Our study clearly showed that the amount of exopolysaccharides produced by Lb. rhamnosus $\mathrm{E} / \mathrm{N}$ depended on the type of the carbohydrate source in the growth medium. A similar relationship was reported by other authors, who suggested that the regulation of the EPS biosynthetic pathway in Lactobacillus and the EPS sugar composition was dependent on the carbohydrate source (Cerning et al., 1994; Grobben et al., 1995; Welman and Maddox, 2003). It has been found that the monosaccharides occurring most frequently in EPS from various Lactobacillus strains were glucose, galactose, and rhamnose (Grobben et al., 1995). Our results confirmed the fact that exopolysaccharides produced by $L b$. rhamnosus $\mathrm{E} / \mathrm{N}$ are mainly heteropolymers consisting of rhamnose, glucose, and mannose when the bacteria were grown on galactose, lactose, or maltose. Rhamnose was present in amounts comparable to the contents of glucose and mannose only when the bacteria were grown in media supplemented with lactose. Lb. rhamnosus $\mathrm{E} / \mathrm{N}$ growing on saccharose as the only carbon source in the medium was able to synthesize homopolysaccharides composed of rhamnose. This is the first report about the capability of the Lactobacillus strain to biosynthesize both homoand heteropolysaccharides.

Hongpattarakere et al. (2012) have proved that EPSs from marine lactic acid bacteria can be used as a pre biotic ingredient in food industry to modulate intestinal microbiota for health benefits. These exopolysaccharides were human non-digestible carbohydrates, which might be used as an additional energy source for intestine microbiota. Bielecka et al. (2002) have shown that a range of bifidobacteria were able to utilize saccharides with a high degree of polymerization. Other authors reported that the broad range of carbohydrates (soybean oligosaccharides, galactooligosaccharides, etc.) were similar to or better than glucose in supporting the growth of bifidobacteria (Su et al., 2007; González et al., 2008). It has been confirmed that carbohydrate metabolism varies considerably among bifidobacterial strains (Pokusaeva et al., 2011). In the present study, the biodegradability of EPSs from Lb. rhamnosus $\mathrm{E} / \mathrm{N}$ was tested in vitro using different species of bifidobacteria. The growth curves on media supplemented with EPSs were compared with bacterial growth on a modified basal Garche's medium containing a minimal carbon source. Our observations indicate that EPSs, which differ in monosaccharide composition, stimulate the growth of bifidobacteria at different rates. RuasMadiedo et al. (2002) related the susceptibility to biological degradation directly to the primary structure of the EPSs. EPSs substituents make their molecules more or less accessible to degradative enzymes. The recently characterized bifidobacterial strains possess extracellular enzymes belonging to glycoside hydrolase families $2,13,36$, and 42 , such as $\alpha$-galactosidases, $ß$-galactosidases, and an enzyme active towards glucooligosaccharides (Pokusaeva et al., 2011). Presence of these hydrolytic enzymes supported the metabolic and nutritional dependencies among colon microorganisms. González et al. (2008) described a novel galactose/lacto- $\mathrm{N}$-biose operon with associated sugar transporters in bifidobacteria. They reported that the bifidogenic effect of human milk was based on complex oligosaccharides. The exopolysaccharides produced by Lb. rhamnosus $\mathrm{E} / \mathrm{N}$ exhibited similar monosaccharide composition as that of the oligosaccharides described previously. In our study, we identified the particular EPSs that significantly enhanced the growth of B. bifidum, B. animalis, B. longum, and B. infantis. The present findings suggest that among the EPSs tested, EPS-Gal and EPS-Lac have the potential to promote the activity of bifidobacterial strains.

Several studies have shown that polysaccharides from bacterial and fungal sources act as antioxidants (Kodali and Sen, 2008; Guo et al., 2010; Pan and Mei, 2010). Very limited information is available concerning the mechanisms of the antioxidant action of polysaccharides at the molecular level. Our results suggest that antioxidant activity is strongly influenced by the substrate used in the oxidative reaction, but also show that various EPSs from Lb.rhamnosus $\mathrm{E} / \mathrm{N}$ trigger diverse 
antioxidant effects. These properties may be dependent on the arrangement of monosaccharides, as well as the type of glycosidic linkages of the polysaccharide and its conformation (Kumar et al., 2007). However, with the use two methods, ABTS/myoglobin and ABTS/potassium persulphate, a significant antioxidant effect was observed for EPS-Gal, EPS-Lac, and EPS-Suc.

In a conclusion, the EPSs produced by Lb. rhamnosus $\mathrm{E} / \mathrm{N}$ grown on five different carbon sources showed bifidogenic and antioxidant activities. It was also found that the level of biological activity was depended on the type of exopolysaccharide. Modification of the growth medium by changing the carbohydrate source is not only a way to optimize the yield of EPS, but also to modify EPS composition. One of the valuable applications of lactic acid bacteria is the possibility to use them to compose complex starter cultures containing probiotic LAB and Bifidobacterium strains, which exhibit health-promoting characteristics. The relationship between the physicochemical characteristics of bacterial exopolysaccharides and their biological function still remains to be elucidated. Further investigations are required to determine the physiological mechanisms of their prebiotic, bifidogenic, and antioxidant effects.

\section{Literature}

Badel S., T. Bernardi and P. Michaud. 2011. New perspectives for Lactobacilli exopolysaccharides. Biotechnol. Advances 29: 54-66. Bielecka M., E. Biedrzycka and A. Majkowska. 2002. Selection of probiotics and prebiotics for synbiotics and confirmation of their in vivo effectiveness. Food Res. Int. 35: 125-131.

Bradford M.M. 1976. A rapid and sensitive method for the quantitation of microgram quantities of protein utilizing the principle of protein-dye binding. Anal. Biochem. 72: 248-254.

Cerning J., C.M.G.C. Renard, J.F. Thibault, C. Bouillanne, M. Landon, M. Desmazeaud and L. Topisirovic. 1994. Carbon source requirements for exopolysasccharide production by Lactobacillus casei CG11 and partial structure analysis of the polymer. Appl. Environ. Microbiol. 60: 3914-3919.

Chabot S., et al. 2001. Exopolysaccharides from Lactobacillus rhamnosus RW-9595M stimulate TNF, IL-6 and IL-12 in human and mouse cultured immunocompetent cells, and IFN $-\gamma$ in mouse splenocytes. Lait 81: 683-697.

Dal Bello F., J. Walter, C. Hertel and W.P. Hammes. 2001. In vitro study of prebiotic properties of levan-type exopolysaccharides from Lactobacilli and non-digestible carbohydrates using denaturing gradient gel electrophoresis system. Appl. Microbiol. 24: 232-237.

de Man J.C., M. Rogosa and E. Sharpe. 1960. A medium for the cultivation of the lactobacilli. J. Appl. Bacteriol. 23: 130-135.

De Vuyst L. and B. Degeest. 1999. Heteropolysaccharides from lactic acid bacteria. FEMS Microbiol. Rev. 23: 153-177.

Duboc P. and B. Mollet. 2001. Applications of exopolysaccharides in the dairy industry. Int. Dairy J. 11: 759-768.

Dubois M., K.A. Gilles, J.K. Hamilton, P.A. Rebers and F. Smith. 1956. Colorimetric method for the determination of sugars and related substances. Anal. Chem. 28: 350-356.

Espinosa-Martos I. and P. Rupérez. 2009. Indigestible fraction of okara from soybean: composition, physicochemical properties and in vitro fermentability by pure cultures of Lactobacillus acidophilus and Bifidobacterium bifidum. Eur. Food Res. Technol. 228: 685-693. González R., E.S. Klaassens, E. Malinen, W.M. de Vos and E.E. Vaughan. 2008. Differential transcriptional response of Bifidobacterium longum to human milk, formula milk, and galactooligosaccharide. Appl. Environ. Microbiol. 74(15): 4686-4694.

Grobben G.J., J. Sikkema, M.R. Smith and J.A.M. De Bont. 1995. Production of extracellular polysaccharides by Lactobacillus delbrueckii ssp. bulgaricus NCFB 2772 grown in a chemically defined medium. J. Appl. Bacteriol. 79: 103-107.

Grobben G.J., M.R. Smith, J. Sikkema and J.A.M. De Bont. 1996. Influence of fructose and glucose on the production of exopolysaccharides and the activity of enzymes involved in the sugar metabolism and the synthesis of sugar nucleotides in Lactobacillus delbrueckii subsp. bulgaricus NCFB 2772. Appl. Microbiol. Biotechnol. 46: 279-284.

Guo S., W. Mao, Y. Han, X. Zhang, et al. 2010. Structural characteristics and antioxidant activities of the exracellular polysaccharides produced by marine bacterium Edwardisiella tarda. Bioresour. Technol. 101: 4729-4732.

Hugenholtz J. and E. Smid. 2002. Nutraceutical production with food-grade microorganism. Curr. Opinion Biotechnol. 13: 497-507. Hongpattarakere T., N. Cherntong, S. Wichienchot, S. Kolida and R.A. Rastall. 2012. In vitro prebiotic evaluation of exopolysaccharides produced by marine isolated lactic acid bacteria. Carbohydrate Polymers 87: 846- 852.

Kodali V.P. and R. Sen. 2008. Antioxidant and free radical scavenging activities of an exopolysaccharides from a probiotic bacterium. Biotechnol J. 3: 245-251.

Korakli M., M.G. Gänzle and R.F. Vogel. 2002. Metabolism by bifidobacteria and lactic acid bacteria of polysaccharides from wheat and rye, and exopolysaccharides produced by Lactobacillus sanfranciscensis. J. Appl. Microbiol. 92: 958-965.

Kumar A.S., K. Mody and B. Jha. 2007. Bacterial exopolysaccharides - a perception. J. Basic Microbiol. 47: 103-117.

Jolly L., S.J.F. Vincent, P. Duboc and J.R. Neeser. 2002. Exploiting exopolysaccharides from lactic acid bacteria. Antonie Van Leeuwenhoek 82: 367-374.

Liu C.-F., K.-C. Tseng, S.-S. Chiang, B.-H. Lee, W.-H. Hsu and T.-M. Pan. 2011. Immunomodulatory and antioxidant potential of Lactobacillus exopolysaccharides. J. Sci. Food Agric. 91: 2284-2291. Looijesteijn P.J., W.H.M. van Casteren, R. Tuinier, C.H.L. Doeswijk-Voragen and J. Hugenholtz. 2000. Influence of different substrate limitations on the yield, composition and molecular mass of exopolysaccharides produced by Lactococcus lactis subsp. cremoris in continuous cultures. J. Appl. Microbiol. 89: 116-122.

Miller N.J., C. Rice-Evans, M.J. Davies, V. Gopinathan and A. Milner. 1993. A novel method for measuring antioxidant capacity and its application to monitoring the antioxidant status in premature neonates. Cli. Sci. 84: 407-412.

Pan D. and X. Mei. 2010. Antioxidant activity of an exopolysaccharide purified from Lactococcus lactis subsp. lactis 12. Carbohydrate Polymers 80: 908-914.

Pieretti G., G. Puopolo, S. Carillo, A. Zoina, R. Lanzetta, M. Parrilli, A. Evidente and M.M. Corsaro. 2011. Structural characterization of the O-chain polysaccharide from an environmentally beneficial bacterium Pseudomonas chlororaphis subsp. aureofaciens strain M71. Carbohydr. Res. 346: 2705-2709.

Pokusaeva K., G.F. Fitzgerald and D. van Sinderen. 2011. Carbohydrate metabolism in Bifidobacteria. Genes Nutr. 6: 285-306.

Que N.L.S., S. Lin, R.J. Cotter and C.R.H. Raetz. 2000. Purification and mass spectrometry of six lipid A species from the bacterial endosymbiont Rhizobium etli. Demonstration of a conserved distal unit and a variable proximal portion. J. Biol. Chem. 275: 28006-28016. 
Rasic J.L. 1990. Culture media for detection and enumeration of the bifidobacteria in fermented milk products. Bulletin of IDF 252: 24-31.

Re R., N. Pellegrini, A. Proteggente, A. Pannala, M. Yang and C. RiceEvans. 1999. Antioxidant activity applying an improved ABTS radical cation decolorization assay. Free Radic. Biol. Med. 26: 1231-1237. Ruas-Madiedo P., J. Hugenholtz and P. Zoon. 2002. An overview on the functionality of exopolysaccharides produced by lactic acid bacteria. Int. Dairy Sci. 12: 163-171.
Sawardeker J.S., J.H. Sloneker and A.R. Jeans. 1965. Quantitative determinations of monosaccharides as their alditol acetates by gas liquid chromatography. Anal. Chem. 37: 1602-1604.

Su P., A. Henriksson and H. Mitchell. 2007. Selected prebiotics support the growth of probiotic mono-cultures in vitro. Anaerobe 13: 134-139.

Welman A.D. and I.S. Maddox. 2003. Exopolysaccharides from lactic acid bacteria: perspectives and challenges. Trends Biotechnol. 21(6): 269-274. 